\title{
O PAPEL DA INDEXAÇÃO COMO FATOR PRINCIPAL NA VISIBILIDADE DOS PERIÓDICOS CIENTÍFICOS
}

\author{
Gildenir Carolino Santos ${ }^{1}$
}

\author{
Como citar: \\ SANTOS, G. C. O papel da indexação como fator principal na visibilidade dos periódicos científicos. In: ABEC \\ MEETING, 1, 2017, Curitiba. Anais... Curitiba: Associação Brasileira de Editores Científicos, 2017. p. 25-31. \\ http://dx.doi.org/10.21452/abecmeeting.2017.005
}

\begin{abstract}
Resumo: No mundo da área do tratamento da informação, o ato da indexação é o processo de transferência e descrição analítica da informação mais importante da área da Biblioteconomia. É por meio da indexação que sabemos como determinado termo ou assunto registrados de forma padronizada nos sistemas e recursos informacionais são encontrados, possibilitando dessa forma o reconhecimento no meio científico, e consequentemente a visibilidade das publicações científicas nos canais de indexação. Sendo assim, o presente trabalho tem como objetivo apresentar o papel da indexação como fator principal na visibilidade dos periódicos científicos, tendo em vista que a indexação está classificada em três tipos de fontes: públicas, privadas e autônomas. Por esse motivo, o texto se propõe a conceituar essas fontes, bem como distinguir o que são indexadores e divulgadores científicos, e como o editor percorre o caminho para chegar nesses indexadores para dar visibilidade aos seus periódicos. Por meio de um estudo experimental em trabalhos com editoria científica, na qual o autor deste trabalho realiza há anos apresentam-se conceituações e definições para se distinguir, inclusive, os tipos de recursos mais apropriados para solicitação de indexação por parte dos editores de periódicos. Conclui-se, diagnosticando por meio dessa classificação o que são indexadores e divulgadores que consolidam a visibilidade e qualificação dos periódicos no ambiente científico por meio destes recursos informacionais, apontado as vantagens para o editor na indexação da publicação.
\end{abstract}

Palavras-chave: Indexação. Periódicos científicos. Visibilidade científica.

Abstract: In the world of information processing, the act of indexing is the process of transfer and analytical description of the most important information in the area of Librarianship. It is through the indexation that we know how a term or subject registered in a standardized way in the systems and informational resources are found, thus enabling its recognition in the scientific environment, and consequently the visibility of the scientific publications in the indexing channels. Thus, the present work aims to present the role of indexing as the main factor in the visibility of scientific journals, considering that indexing is classified in three types of sources: public, private and autonomous. For this reason, the text proposes to conceptualize these sources, as well as distinguish what are scientific indexers and scientific disseminators. Also, describes the paths the editor follows to reach these indexers, in order to give visibility to their journals. Through an experimental study working with scientific publishing, a role that the author has been dealing with for years, have been presented concepts and definitions to distinguish the most appropriate types of resources that editors of periodicals should request for indexation. It concludes diagnosing, through this classification, what are indexers and disseminators that consolidate the visibility and qualification of journals in the scientific environment. Points out the advantages the publisher gets by indexing its publications using these informational resources,

Keywords: Indexing. Scientific journals. Scientific visibility.

\section{INTRODUÇÃO}

O ato da indexação é o processo de transferência e descrição analítica da informação mais importante da área da Biblioteconomia. É por meio da indexação que sabemos como determinado termo ou assunto registrados de forma padronizada nos sistemas e recursos informacionais são encontrados. (SANTOS; FERREIRA, 2016).

Esses recursos informacionais denominados base de dados, diretórios, portais e índices e indicam onde uma ou mais publicações (periódicos, revistas, jornais, boletim, etc.) 
encontram-se indexadas de maneira manual ou automatizada, destinando-se a eles os responsáveis pelo grande número de informações e dados armazenados de forma segura e padronizada. (SANTOS, 2017).

Pode-se dizer que portais ou diretórios são considerados formas semiestruturadas de indexação por oferecerem informação de maneira estática ou dinâmica, enquanto que nas bases de dados são relativamente mais complexas e estruturadas.

A busca dos editores de periódicos e revistas científicas pela indexação nesses mecanismos nos dias de hoje é relativamente elevada e concorrida. Uma publicação periódica lançada com a mesma temática em alguma parte do planeta corre o risco de competir com outras que já existiam há mais tempo e que já tenham maior prestígio e reconhecimento do que aquela que nasceu recentemente nas diferentes bases de dados.

Para concorrer a uma indexação em determinadas fontes de indexação, ou melhor, bases, diretórios ou portais especializados, o interessado, no caso o editor da publicação, deve seguir os critérios rigorosamente publicados nas organizações gestoras desses mecanismos na língua original em que são mantidos. (SANTOS, 2017).

Saber escolher as fontes de indexação é algo muito importante para a contextualização do periódico e para a visibilidade dele por diversas instituições e fornecedores.

\section{TIPOLOGIA DAS FONTES}

Hoje no mercado da informação existem várias bases de dados e diretórios voltados a temáticas gerais e específicas para condicionar o recepcionamento dos periódicos aos critérios de avaliação e indexação apresentados pelas principais bases de dados e diretórios de indexação, e até mesmo por alguns portais de indexação importantes no meio acadêmico. As regras e os critérios são tanto para as fontes privadas quanto para as fontes públicas.

As fontes são organizadas em três tipos:

- públicas;

- privadas ou proprietárias; e

- autônomas. (SANTOS, 2015).

As fontes públicas são aquelas fontes administradas por uma entidade pública ou não governamental (ONG), visando à expansão e disseminação da informação de uma determinada área de atuação, não almejando fins lucrativos. Exemplos: Edubase, Portal de 
Periódicos Capes, DOAJ, Educ@, ERIC, Latindex, Lilacs, PubMed. (SANTOS, 2015, 2016, 2017).

As fontes privadas ou proprietárias são fontes registradas e administradas por uma empresa (fornecedores comerciais) que comercializam os seus produtos, visando à disseminação de uma ou mais áreas do conhecimento. Como exemplos, citamos: Web of Science (Thomson Reuters); Scopus (SciVerse / Elsevier); Academic OneFile (Gale Cengage); entre outros fornecedores, tais como: ProQuest, EBSCO Host, Emerald Group Publishing. (SANTOS, 2015, 2016, 2017).

Como exemplo de base de dados privada, citamos a "Web of Science (WoS) que caracteriza-se como um conjunto de bases de dados compilados pelo ISI (Institute for Scientific Information) que permite a recuperação de trabalhos publicados em importantes fontes de informações internacionais, apresentando as referências bibliográficas contidas nos mesmos e possibilita ver quais os artigos citados por determinado artigo, ou verificar quantas vezes um artigo foi citado e por quem”. (ROCHA; HOFFMAN, 2014). Hoje, essa grande base de dados está sendo gerenciado pela empresa-editora Clarivate Analytics ${ }^{1}$, e facilitando de certa forma, a aceitação de publicações periódicas de diversas nacionalidades, por meio da Emerging Source Citation Index (ESCI), que abriga os periódicos emergentes para que os mesmos possam obter métricas suficientes para migrarem posteriormente para a base geral da WoS

Por último, temos as fontes autônomas que são administradas por uma equipe autônoma sem fins lucrativos, visando à disseminação da informação de todas as áreas do conhecimento de acesso aberto, por exemplo, Cite Factor, Sumários.org, Genamics, Academic Journals Database, E-LIS. (SANTOS, 2015, 2016, 2017).

Além dessa organização, as fontes estão categorizadas em quatro níveis de reconhecimento:

- local;

- regional;

- nacional; e

- internacional (SANTOS, 2015).

A categorização das fontes também pode dar-se de forma única ou híbrida, ou seja, ela pode ser ao mesmo tempo local, mas considerada também como regional, e assim por diante - entretanto, considera-se a forma mais atuante da categoria nessa classificação.

\footnotetext{
${ }^{1}$ Disponível em: <https://clarivate.com/>. Acesso em: 20 out. 2017. 


\section{FONTES INDEXADORAS: BASES DE DADOS, DIRETÓRIOS, PORTAIS E ÍNDICES ${ }^{2}$}

Existem bases de dados e diretórios que não são exigentes assim, exigindo do interessado em indexar sua publicação apenas um registro no cadastro, disponibilizado no site ou por e-mail, mencionando os dados da publicação, e tendo às vezes que anexar o último fascículo para análise, somente. Em seguida, o interessado aguarda o editor responsável pela base de dados ou diretório responder confirmando o aceite.

Além das bases de dados e diretórios, também existem os portais indexadores que cada vez surgem mais para organizar e indexar grandes coleções de publicações periódicas, sendo parte deles estruturados por ferramentas gerenciadoras de publicações, como o OJS Open Journal System, e o SciELO - Scientific Elctronic Library Online.

Existem os portais de indexação abertos e os restritos. Os portais de indexação abertos são aqueles de domínio aberto, constituídos por uma instituição ou empresa que os administra, em que o editor pode submeter sua publicação para indexação com ou sem análise. Os de acesso restrito são aqueles de domínio exclusivo de uma instituição ou empresa que o administra. A intenção apenas é de indexar publicações editadas na própria instituição ou por uma rede cooperativa específica.

Segundo dados estatísticos do PKP - Public Knowledge Project, idealizador e criador da ferramenta $\mathrm{OJS}^{3}$, existem atualmente no mundo, utilizando e operando com essa ferramenta no que diz respeito ao gerenciamento eletrônico de publicações, mais de 10.178 periódicos e 445.413 artigos de acesso aberto. Esse dado aponta para a grande e crescente busca dos editores pela indexação das suas publicações fomentadas pelo OJS, como periódicos ou portal temático, tornando-o também, em portal indexador restrito da instituição que o administra ou de um organismo de pesquisa. Esse indicador também mostra que o sistema oferece todos os quesitos para que uma publicação possa ser bem avaliada e aceita nas diversas fontes de indexação.

Outro tipo de indexador são os índices que indexam as referências bibliográficas citadas em cada artigo componente de periódicos científicos parceiros, constituindo-se assim maneira alternativa de recuperação de informação, que posteriormente passam a ser

\footnotetext{
${ }^{2}$ Para saber mais sobre bases de dados, diretórios, portais indexadores e índices, bem como outros divulgadores, consulte o Infográfico de Recursos Informacionais, disponível em: <http://www.sbu.unicamp.br/seer/ojs/index.php/ppec/article/view/9056>. Acesso em: 20 out. 2017.

3 Public Knowledge Project. OJS stats: number of journals using Open Journal Systems. Disponível em: <https://pkp.sfu.ca/ojs/ojs-usage/ojs-stats/ >. Acesso em: 20 out. 2017. (Dados informados no site até o ano de 2016).
} 
contabilizadas, originando indicadores de citação. (MUGNAINE; STREHL, 2008 apud SALES, 2013).

Vale lembrar que muitos editores mencionam em suas publicações os divulgadores como indexadores, que na verdade não o são. Como divulgadores, destacamos os seguintes:

- catálogos de bibliotecas - exemplo: catálogo bibliográfico da UNICAMP, da USP, da UNESP, etc.;

- bibliotecas virtuais - exemplo: Biblioteca Digital da UNICAMP, da USP, da UNESP, etc.;

- indicadores de avaliação e estratificação - exemplo: Qualis/Capes;

- indicadores de visibilidade de métricas: - exemplo: SCImago/Scopus; Google Analytics;

- $\quad$ sites institucionais - exemplo: Portal do MEC, site da instituição, etc.;

- redes sociais acadêmicas - exemplo: Academia.edu; Research Gate, etc.;

- $\quad$ associações - exemplo: ANPEd, ANPOCS, ABEC ${ }^{4}$, Crossref, etc.;

- identificadores persistentes - exemplo: $\mathrm{DOI}^{5}$ e ORCID 6 .

- e outros

Sendo assim, para que a publicação possa ter uma certificação de qualidade, com a indicação dos seus indexadores visíveis ao publico leitor, seria aconselhável que o editor classificasse distintamente dentro da publicação, indicando na página de políticas do OJS, as informações que diferenciam os indexadores dos divulgadores, facilitando dessa forma, a melhor compreensão dos leitores e interessado nas publicações, bem como organismos avaliadores, como o Qualis/Capes que avaliam os periódicos dos programas de pós-graduação não errando nesse quesito, para informar corretamente onde a publicação é indexada. (SANTOS, 2011).

\section{CONSIDERAÇÕES FINAIS}

Considerando as palavras de Packer (2014), é possível afirmar que "a indexação, em particular a de periódicos, é parte integral do fluxo da comunicação científica, controle bibliográfico, preservação, bibliometria, cienciomentria".

Os periódicos com base no cumprimento dos padrões básicos de comunicação científica e nas linhas prioritárias de profissionalização, internacionalização e sustentabilidade

\footnotetext{
${ }^{4}$ Associação Brasileira De Editores Científicos. Disponível em: <https://www.abecbrasil.org.br/novo/>. Acesso em: 20 out. 2017.

${ }^{5}$ DOI Foundation. Disponível em:< http://www.doi.org/>. Acesso em: 24 abr. 2017.

${ }^{6}$ ORCID. Disponível em: <http://orcid.org>. Acesso em: 20 out. 2017.
} 
garantirão, com certeza, de forma imediata, a indexação dessas publicações nas principais bases, diretórios, portais e índices importantes. E, finalmente, deve haver constante parceria entre o editor e o bibliotecário para promover e qualificar a publicação da instituição. (PACKER, 2014).

Pode-se afirmar que a visibilidade e os benefícios em se ter uma publicação indexada são muito grandes, pois de acordo com Sales (2013, p. 32), “o periódico deve pleitear a inclusão em bases de dados nacionais e internacionais, de acordo com a área temática que abrange. Quanto maior o número de bases de dados nacionais e internacionais em que figurar, maior será a valorização de qualidade, produtividade e sua difusão indireta”.

Enfim, além de prestar visibilidade à sua publicação, o editor reunirá um elenco de vantagens e benefícios com a indexação do periódico por meio de alguma base de dados, diretório ou portal, como as seguintes: padronização de dados de uma coleção; reunião dos assuntos semelhantes de uma determinada área; recuperação da informação especializada; facilitar ao acesso e recuperação das informações registradas com seus metadados; divulgação da produção científica; manutenção do usuário permanentemente focado na sua área de interesse em um único local especializado; agregará valor a publicação periódica; reconhecimento pelos pares na área de atuação; promoção da visibilidade (nacional e internacional) para a publicação tanto no âmbito institucional quanto no meio privado, por meio dos fornecedores de fontes de indexação.

Os periódicos com base no cumprimento dos padrões básicos de comunicação científica e nas linhas prioritárias de profissionalização, internacionalização e sustentabilidade garantirão com certeza de forma imediata a indexação dessas publicações nas principais bases, diretórios, portais e índices importantes. E por último, deve haver constante parceria entre o editor e o bibliotecário para promover e qualificar a publicação da instituição. (SANTOS, 2017).

\section{REFERÊNCIAS}

PARCKER, Abel. Visibilidade e impacto internacional: os desafios da internacionalização dos periódicos do Brasil. Apresentação em Power Point. 34 slides. 2014. Disponível em: $<$ http://www.escritacientifica.sc.usp.br/wp-content/uploads/MD Os_desafios da_internacionalizacao_dos_periodicos_do_Brasil_Abel_Packer.pdf $>$. Acesso em: 10 mar. 2016.

ROCHA, M. B.; HOFFMAN, W. A. M. A produção científica brasileira sobre gestão do conhecimento na base de dados Web of Science. In: CONGRESSO BRASILEIRO DE GESTÃO DO CONHECIMENTO, 12., 2014, Florianópolis. Anais eletrônicos do... São Paulo, SP: SBGC/KMB, 2014. Disponível em: <http://www.kmbrasil.com/anais/ arquivos/trabalhos/76.pdf>. Acesso em: 10 mar. 2016. 
SALES, Denise Peres. Critérios de avaliação da produção científica em Ciências Sociais Aplicadas: inquirindo as bases de dados. 2013. Dissertação (Mestrado em Cultura e Informação) - Escola de Comunicações e Artes, Universidade de São Paulo, São Paulo, 2013. Disponível em: <http://www.teses.usp.br/teses/disponiveis/27/27151/ tde-26052015-122438/>. Acesso em: 10 mar. 2016.

SANTOS, Gildenir Carolino. Fontes de indexação para periódicos científicos: um guia para bibliotecários e editores. Campinas, SP: E-Color, 2011. 99 p. (Manuais técnicos BFE, n.6). ISBN 9788563058188. Disponível em: <http://eprints.rclis.org/ 16898/1/fontesISBN9788563058188.pdf>. Acesso em: 24 abr. 2017.

SANTOS, Gildenir Carolino. Indexação de publicações acadêmicas universitárias: portais temáticos e suas vantagens para as publicações periódicas. In: ALMEIDA, Maria de Lourdes Pinto de (Org.). Produção do conhecimento científico e a formação do pesquisador na América Latina: as investigações de políticas educacionais em xeque!. Campinas, SP: Mercado de Letras, 2017. p.231-246. ISBN 978-85-7591-439-7.

SANTOS, Gildenir Carolino. Minicurso Onde indexar seu periódico. In: ENCONTRO NACIONAL DE EDITORES CIENTÍFICOS, 15.: 2015, Florianópolis. Minicursos... Florianopólis: ABEC, 2015. 78 slides Power Point. Disponível em: <https://www. abecbrasil.org.br/eventos/xv_enec/index.asp>. Acesso em: 24 abr. 2017.

SANTOS, Gildenir Carolino. Sustentabilidade e visibilidade da produção científica: a construção do Portal de Periódicos Eletrônicos Científicos da UNICAMP. In: SEMINÁRIO NACIONAL DE BIBLIOTECAS UNIVERSITÁRIAS, 18: 2016, Manaus. Anais eletrônicos... Manaus: UFAM, 2016. Disponível em: <http://periodicos.ufam.edu.br/anaissnbu/article/view/3283 > . Acesso em: 24 abr. 2017.

SANTOS, Gildenir Carolino; FERREIRA, Danielle Thiago. Registrando, indexando e preservando digitalmente a RDBCI: indicadores da produção de 2003 a 2016. RDBCI:

Revista Digital de Biblioteconomia e Ciência da Informação, Campinas, SP, v. 14, n. 3, p. 541-560, set./dez. 2016. ISSN 1678-765X. Disponível em: <http://periodicos.sbu. unicamp.br/ojs/index.php/rdbci/article/view/8646317> . Acesso em: 24 abr. 2017. doi:https://doi.org/10.20396/rdbci.v14i3.8646317. 